\title{
Anti-anxiety effect of methanol extract of Pericarpium zanthoxyli using a strychnine-sensitive glycine receptor model
}

\author{
Tae Eun Kim, Jung Hwa Jung, Saehee Yoon and Sung-Jin Kim* \\ Department of Pharmacology and Toxicology, Metabolic Diseases Research Laboratory, School of Dentistry, Kyung Hee \\ University, Seoul, Republic of Korea
}

*For correspondence: Email: kimsj@khu.ac.kr; Tel: +82-2-961-0868; Fax: +82-2-960-0867

Received: 16 July 2015

Revised accepted: 6 March 2016

\begin{abstract}
Purpose: To determine if the methanol extract of Pericarpium zanthoxyli exerts anti-anxiety effects and also to explore any probable anti-anxiety mechanism in vivo.

Methods: The staircase test, elevated plus maze test, rota-rod treadmill test and convulsions induced by strychnine and picrotoxin on mice were tested to identify potential mechanism of anti-anxiety activity of the plant extract.

Results: The plant extract (10 mg/kg, p.o.) significantly reduced rearing numbers in the staircase test while it increased the time spent in the open arms as well as the number of entries to the open arms in the elevated plus maze test, suggesting that it has significant anti-anxiety activity. Furthermore, the extract inhibited strychnine-induced convulsion. However, it had little effect on picrotoxin-induced convulsion, suggesting that its anti-anxiety activity may be linked to strychnine-sensitive glycine receptor and not GABA receptor.

Conclusion: These results suggest that the Pericarpium zanthoxyli extract may be beneficial for the control of anxiety.
\end{abstract}

Keywords: Anti-anxiety, Pericarpium zanthoxyli, Glycine Receptor, GABA Receptor

\begin{abstract}
Tropical Journal of Pharmaceutical Research is indexed by Science Citation Index (SciSearch), Scopus, International Pharmaceutical Abstract, Chemical Abstracts, Embase, Index Copernicus, EBSCO, African Index Medicus, JournalSeek, Journal Citation Reports/Science Edition, Directory of Open Access Journals (DOAJ), African Journal Online, Bioline International, Open-J-Gate and Pharmacy Abstracts
\end{abstract}

\section{INTRODUCTION}

The genus Zanthoxylum has more than 200 species belonging to the Rutaceae family. These species have been used as drugs in traditional medicine systems in Central, South, Southeast and East Asia [1]. Pericarpium zanthoxyli refers to the rind of dried fruits of Zanthoxylum bungeanum Max., Zanthoxylum schinifolium Sieb. et Zucc. and Zanthoxylum piperitum D.C. was mostly distributed in Korea and China [2]. These species are rich in essential oil that promote absorption of the active components in a prescription for their unique properties $[2,3]$.
In traditional medicines, Pericarpium zanthoxyli is widely used for warming the spleen and stomach to relieve pain, killing parasites to relieve itching, cold and painful stomach, diarrhea, indigestion, acute and chronic gastritis, pathogenic wind, epigastric pain, eczema, pruritus, fungal infection, diarrhea, dysentery and toothache [49]. It has been reported that Pericarpium zanthoxyli has insecticidal activity [10], antioxidative activity [2] and inhibits the early stages of adipogenic differentiation [11]. It also has effects on antagonizing ulcer, inflammatory and functional diarrheas, protecting liver and correcting gastrointestinal disorder and analgesic effect to relieve various abdominal pains [9]. 
Anxiety disorder is the most common psychological behavioral disorder and benzodiazepines (BZD) have been widely used to treat for anxiety. But, continued use of BZD have been reported for side effects such as memory impairment, addiction problem and muscle relaxation [12]. Thus, novel treatment strategies for anti-anxiety with few side effects are essential for the safe management of patients. The aim of the present study was to determine the anti-anxiety effect of Pericarpium zanthoxyli extract and its potential mechanisms using animal behavioral experiments.

\section{EXPERIMENTAL}

\section{Animals}

Male ICR mice (23-28 g) were purchased from Hanlim Experimental Animals Co., Korea. They were housed under standard environmental conditions of temperature at $22 \pm 2{ }^{\circ} \mathrm{C}$ under a 12-h light/dark cycle and allowed free access to standard certified rodent diet and tap water. All animal experiments were performed according to the Guide for the Care and Use of Laboratory Animals' published by the National Research Council of the National Academies, USA and the Animal Care and Use Guidelines of Kyung Hee University, Seoul, KOREA.

\section{Reagents and materials}

Strychnine and picrotoxin were purchased from Tocris (USA). Thiopental sodium was kindly provided by JW Pharmaceutical Co. (Korea). All other chemicals were purchased from Sigma Chemical Co. (USA).

\section{Preparation of plant extracts}

Dried aerial parts of Zanthoxylum bungeanum Maxim collected in autumn were purchased from Kyung-Dong Oriental Market, Seoul, Republic of Korea. They were authenticated by Professor Emeritus Chang-SooYook, Department of Oriental Pharmacy, Kyung Hee University, Seoul, Republic of Korea. A quantity (100 g) was cut into small pieces and extracted three times with $70 \%$ methanol $(300 \mathrm{ml})$ for $3 \mathrm{~h}$ via sonication. The resulting methanol extract was concentrated in a rotary evaporator and freeze-dried.

\section{Staircase test}

The stair case test was carried out as described below [13]. A mouse was placed singly on the floor of the box with its back to the staircase. The number of steps (stairs) climbed and the number of rears (rearing) were counted visually over a 3 min period. Climbing was defined as each stair on which the mouse placed all four paws; rearing was defined as each instance the mouse rose on hind legs, either on a stair or leaning against the wall. The number of stairs descended was not taken into account. After each animal had been tested, the box was rapidly cleaned to eliminate any olfactory cue which might modify the behavior of the next animal. The Pericarpium zanthoxyli extract (10 or $90 \mathrm{mg} / \mathrm{kg}$ ) was administered orally using 18 gauge animal feeding needles 60 min before the test. In each experiment, a control group received only saline. Thiopental (25 mg/kg, i.p.) was used as a standard drug.

\section{Elevated plus maze test}

The plus maze, consisting of two open arms (50 $x 10 \mathrm{~cm})$ and two enclosed arms (50 x $10 \times 40$ $\mathrm{cm}$ ) and elevated to a height of $70 \mathrm{~cm}$, was used as described earlier by Pellow et al [14]. Mice were treated with saline or Pericarpium zanthoxyli extract (10 or $90 \mathrm{mg} / \mathrm{kg}$, p.o.) and 60 min later were placed individually in the center of the plus maze, facing the closed arm. The time spent in the closed and open arms and the number of entries in the closed and open arms during the 5-min test period were recorded visually. Trials were recorded and analyzed using the Noldus Ethovision XT software (Noldus Information Technology, Leesburg, VA).

\section{Strychnine-induced convulsions}

Groups of 10 mice within the weight range of 23 and $28 \mathrm{~g}$ were used. They were treated orally with saline or Pericarpium zanthoxyli extract (10 or $90 \mathrm{mg} / \mathrm{kg}$, p.o.). One hour later the mice were injected with $2 \mathrm{mg} / \mathrm{kg}$ strychnine i.p. The time lapse before the occurrence of tonic extensor convulsion and death was noted during a 1-hour period [15].

\section{Picrotoxin-induced convulsions}

Groups of 10 mice within the weight range of 23 and $28 \mathrm{~g}$ were used. They were treated orally with saline or Pericarpium zanthoxyli extract (10 or $90 \mathrm{mg} / \mathrm{kg}$, p.o.). One hour later the mice were injected with $3.5 \mathrm{mg} / \mathrm{kg}$ picrotoxin s.c. The time until occurrence of clonic seizure was noted during a $30-\min$ period [16].

\section{Rotarod test}

Each mouse was trained to run in a Rotarod ( 3 $\mathrm{cm}$ in diameter, $15 \mathrm{rpm}$, Rota-Rod Treadmill, Neo Click Co, Seoul, Korea) until it could remain there for $5 \mathrm{~min}$ without falling. The mice were then 
evaluated in a Rotarod performance test for 5 min, 60 min after saline or Pericarpium zanthoxyli (10 mg/kg, p.o.) treatment [17].

\section{Statistical analysis}

Data analysis was carried out using the Graphpad Prism 4.0 software (GraphPad Software, Inc., La Jolla, CA), and expressed as mean \pm SEM. Statistical analysis of treatment effects was determined using one-way analysis of variance (ANOVA) followed by Tukey's multiple comparison test between groups. $P<$ 0.05 were considered statistically significant.

\section{RESULTS}

Administration of the plant extract $(10 \mathrm{mg} / \mathrm{kg}$, p.o.) did not cause any significant changes in the number of steps climbed (Figure 1A) whereas it caused a decrease in the number of rears (Figure $2 \mathrm{~A}$ ) by $45 \%$ compared to control. When the extract was administered at a dose of 90 $\mathrm{mg} / \mathrm{kg}$, p.o., the number of steps climbed (Fig. $1 \mathrm{~B})$ was not changed, but the number of rears

A

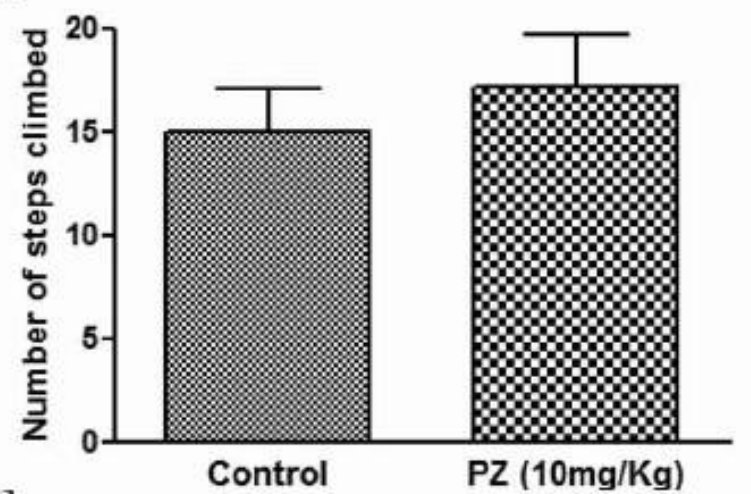

C

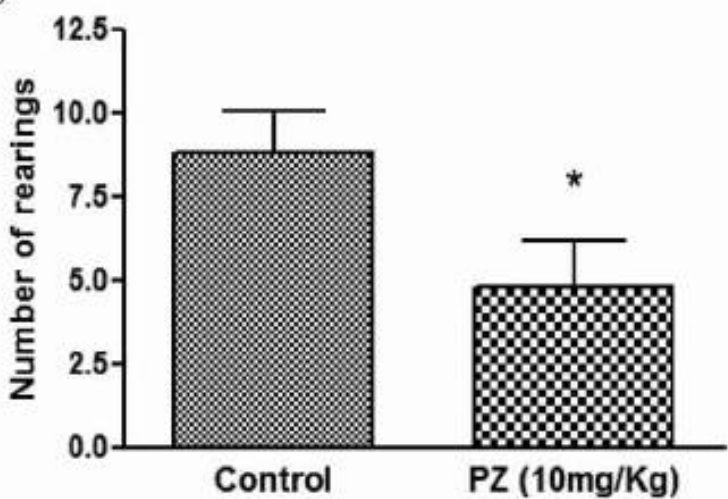

(Fig. 2B) was decreased by $50 \%$ as compared to control.

The Pericarpium zanthoxyli extract had little effect on the number of entries to closed arms (Figure 2B) whereas it caused an increase in the number of open arm entries (Figure $1 \mathrm{~A}$ ) by 2.4fold. The time spent in open arms (Figure 3A) was also significantly increased by the extract to 2.1-fold compared to control while the time spent in closed arms was not affected (Figure 3B).

Thiopental treatment (26 mg/kg, i.p.) caused a 2fold increase in the number of entries in open arms (Figure 2C) as compared to control whereas it had little effect on the number of entries in closed arms (Figure 2D). Thiopental also caused a 4-fold increase in the time spent in open arms as compared to control (Figure 3C), but, the time spent in closed arms was decreased by $27 \%$ as compared to control by thiopental (Figure 3D).

$\mathrm{B}$

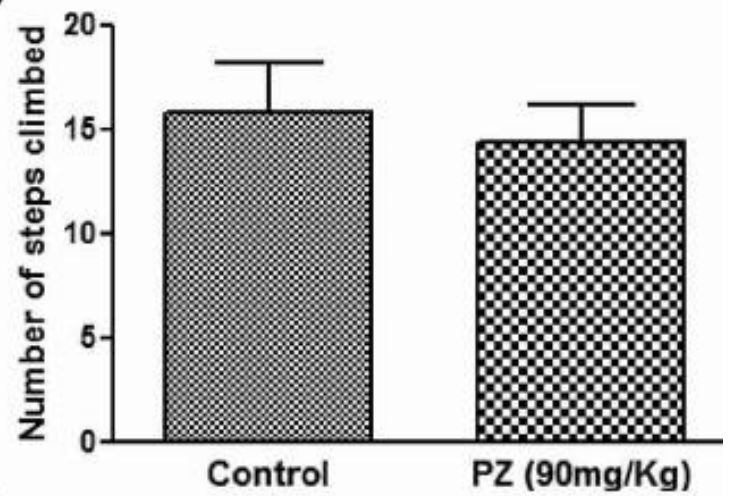

$\mathrm{D}$

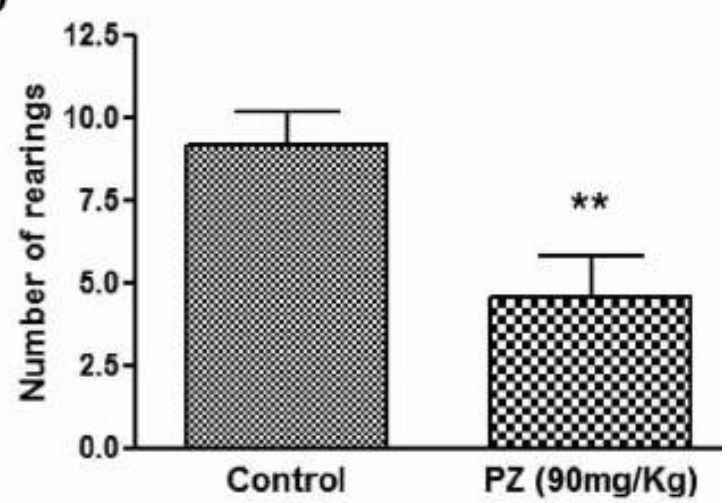

Figure 1: Effect of the Pericarpium zanthoxyli extract on anxiety in the staircase test in mice. Following administration of the Pericarpium zanthoxyli extract (10 or $90 \mathrm{mg} / \mathrm{kg}$, p.o.), the staircase test was performed as described in the Materials and Methods. Data are expressed as mean \pm SEM. ${ }^{*} p<0.05$ compared to the control group; ${ }^{* *} p<0.01$ compared to the control group; (one-way ANOVA followed by Tukey's multiple comparison test, $n=5$ ) 
A

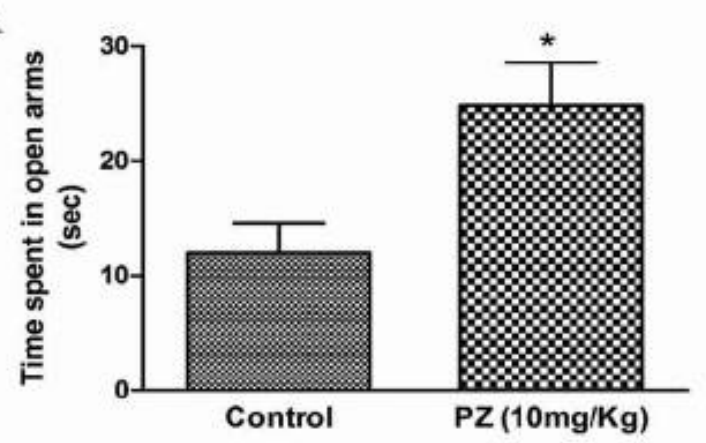

C

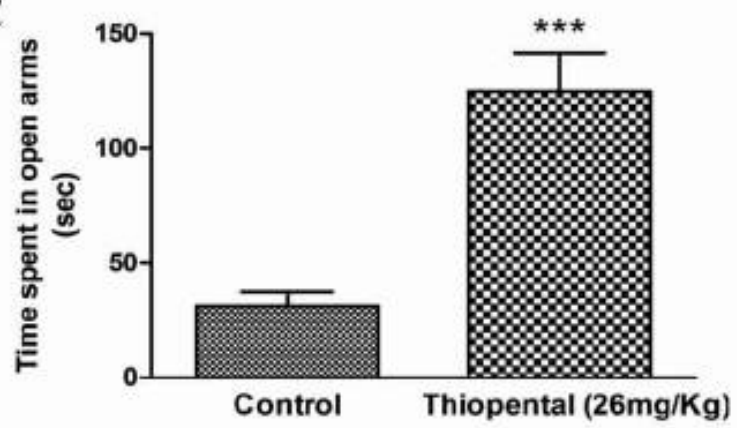

B

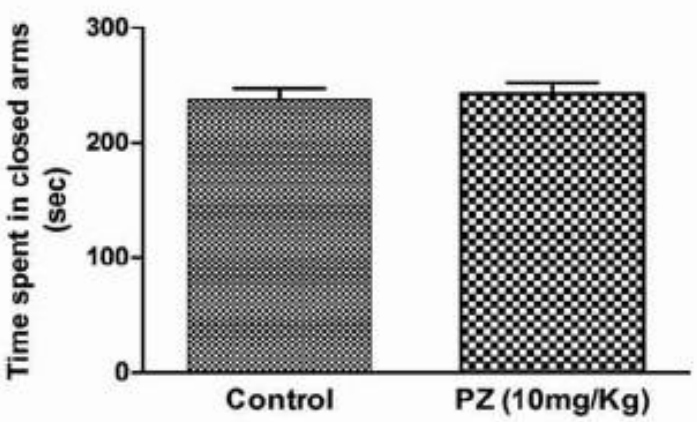

D

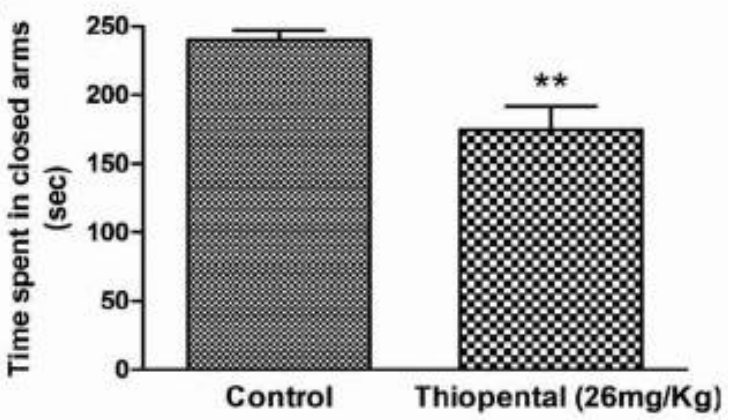

Figure 2: Effects of the Pericarpium zanthoxyli extract and thiopental on anxiety in the elevated plus maze test in mice. Following the administration of the Pericarpium zanthoxyli extract (10 mg/kg, p.o.) or thiopental (26 mg/kg, i.p.), the elevated plus maze test was performed as described in the Materials and Methods. Data are expressed as mean \pm SEM. ${ }^{*} p<0.05,{ }^{* * *} p<0.001$ compared to the control group (one-way ANOVA followed by Tukey's multiple comparison test, $n=5$ )

A

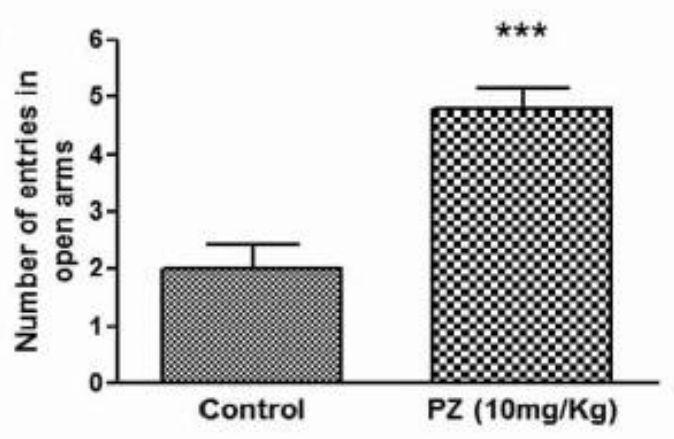

C

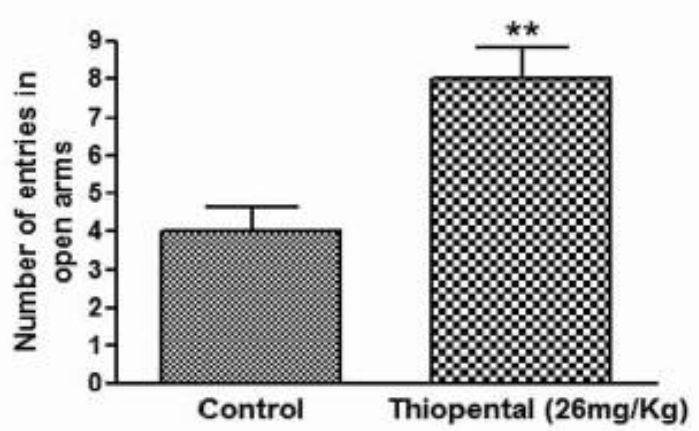

B

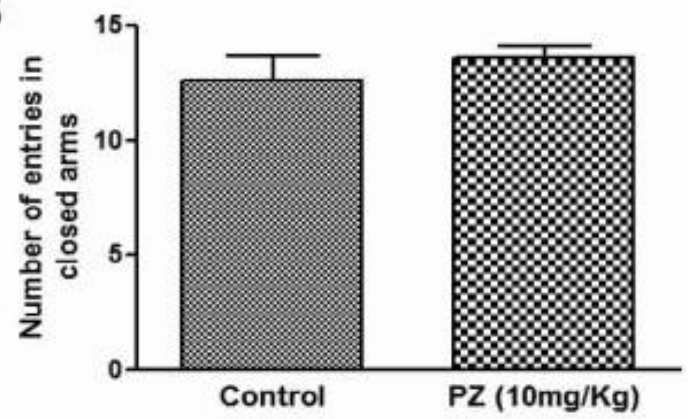

D

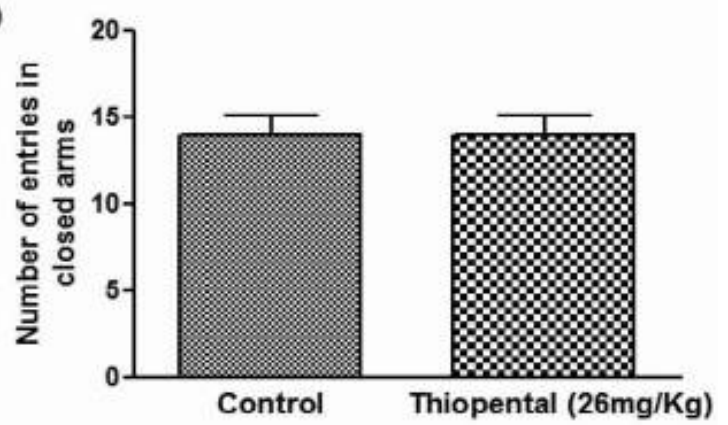

Figure 3: Effects of the Pericarpium zanthoxyli extract and thiopental on anxiety in the elevated plus maze test in mice. Following the administration of the Pericarpium zanthoxyli extract (10 mg/kg, p.o.) or thiopental (26 mg/kg, i.p.), the elevated plus maze test was performed as described in the Materials and Methods. Data are expressed as mean \pm SEM. ${ }^{* *} p<0.01,{ }^{* *} p<0.001$ compared to the control group (one-way ANOVA followed by Tukey's multiple comparison test, $n=5$ ) 
A
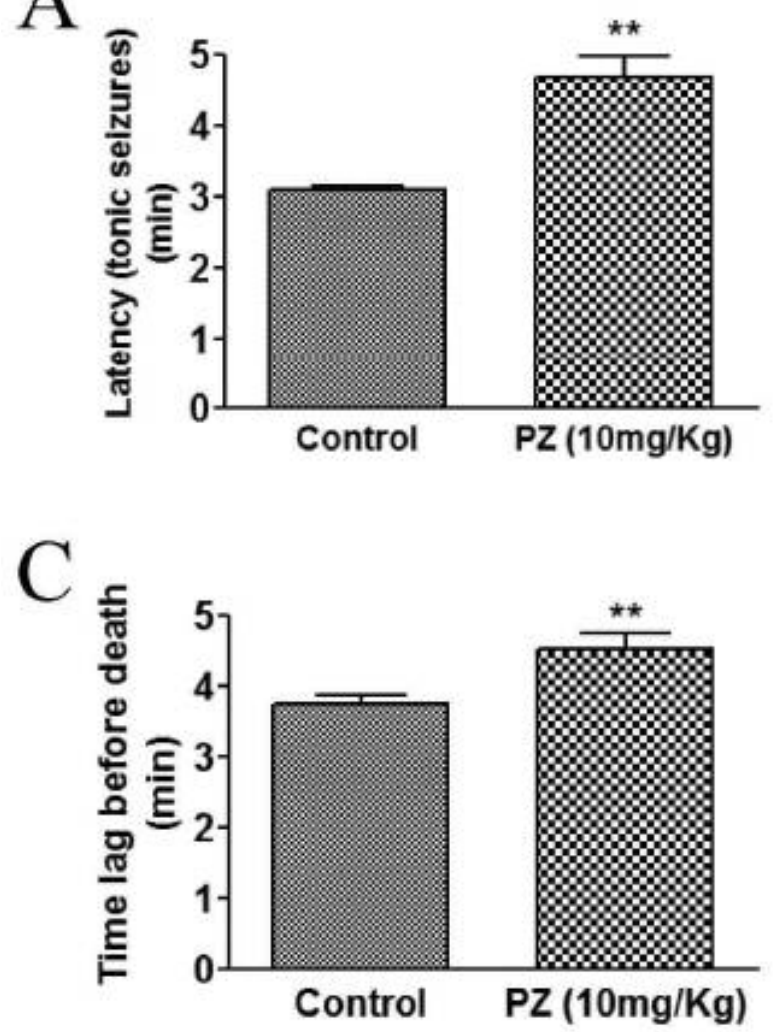

E

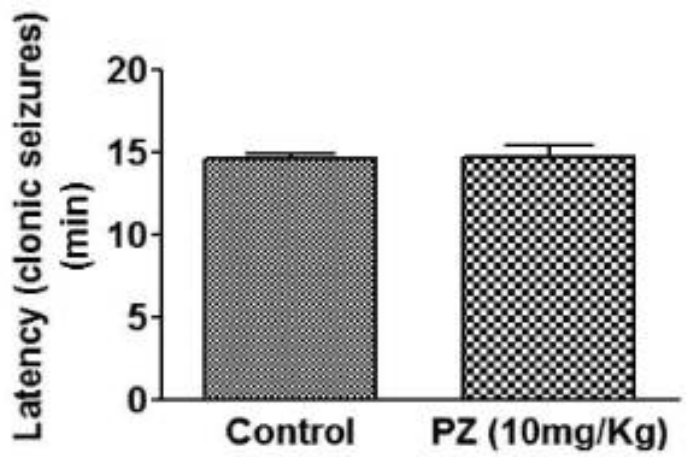

$\mathrm{B}$

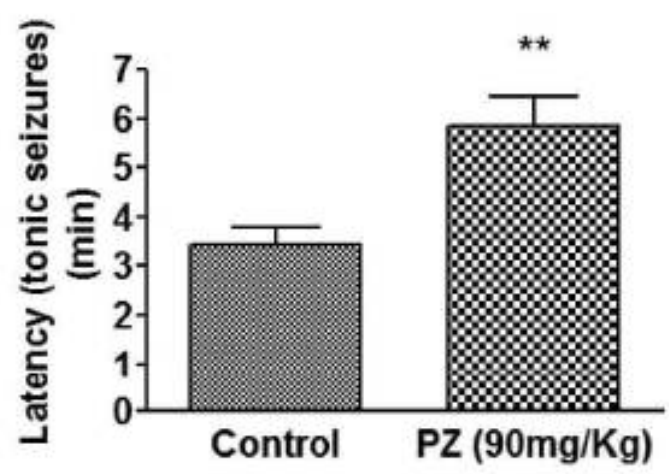

$\mathrm{D}$

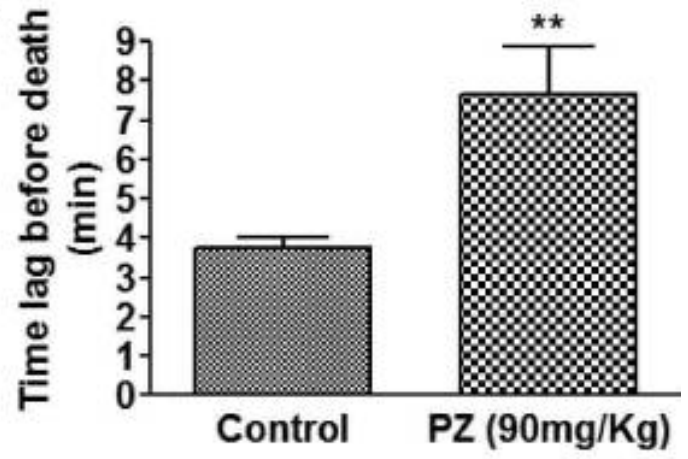

$\mathrm{F}$

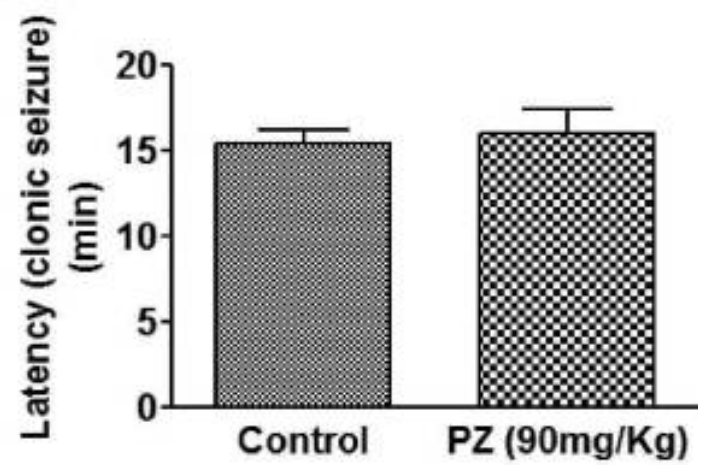

Figure 4: Effect of the Pericarpium zanthoxyli extract on the strychnine- and picrotoxin-induced convulsions in mice. Following the Pericarpium zanthoxyli extract administration (10 or $90 \mathrm{mg} / \mathrm{kg}$, p.o.), convulsion was induced by strychnine or picrotoxin as described in the Materials and Methods. Latency to convulsion and the time lag before death was measured. Data are expressed as mean \pm SEM. ${ }^{* *} p<0.01$ compared to the control group (one-way ANOVA followed by Tukey's multiple comparison test, $n=5$ )

The Pericarpium zanthoxyli extract (10 and 90 $\mathrm{mg} / \mathrm{kg}$, p.o.) increased the latency to the onset of the first clonic seizure caused by strychnine by 51 and $71 \%$ as compared to control, respectively (Figure $4, A-B$ ). It prolonged the induction time of death by 1.21-fold and 2.06-fold respectively as compared to control, (Figure 4, C-4). However, the Pericarpium zanthoxyli extract (10 or $90 \mathrm{mg} / \mathrm{kg}$ ) had not showed any significant effect on the latency to the onset of convulsion caused by picrotoxin (Figure 4, E-F).
The extract $(10 \mathrm{mg} / \mathrm{kg})$ exerted no effect in the Rotarod test as the time spent on rotarod for both control and extracted-treated rats was about 250 $\mathrm{s}$.

\section{DISCUSSION}

Pericarpium zanthoxyli has been widely used as a spice in Asian countries since it has unique aroma and taste [1]. In addition, it has been 
found that Pericarpium zanthoxyli has various pharmacological effects such as analgesic, antimicrobial, anti-oxidative and anti-inflammatory actions [2,7-10,18-24]. It also has essential oils up to $11 \%$ and their aroma affects a patient's mood [25]. The above findings prompted us to investigate whether the methanolic extract of Pericarpium zanthoxyli has any anti-anxiety activity in experimental animals.

In the present study, Pericarpium zanthoxyli extract has a significant anti-anxiety activity in mice as evidenced by behavioral experiments such as the elevated plus maze test and staircase test. The elevated plus maze test and staircase test are used by many investigators as common tools for the study of anxiety of rodents such as mice and rats. In the staircase test, the rearing number is considered as an index of anxiety whereas the number of steps climbed is representative of the explorative activity of animals [13]. The Pericarpium zanthoxyli extract at a concentration of $10 \mathrm{mg} / \mathrm{kg}$ significantly decreased the number of rears while the number of steps climbed was not affected by the extract, suggesting that the Pericarpium zanthoxyli extract has the ability to exert anti-anxiety action with little effect on the explorative activity. Based upon these results, it is reasonable to propose that the Pericarpium zanthoxyli extract's antianxiety activity was not due to a decrease of explorative action but due to bona fide CNS sedative action. To further support the Pericarpium zanthoxyli extract's anti-anxiety action, elevated plus maze tests were also performed. In the elevated plus maze test, the time spent in the open arms and the number of entries to open arms are considered to be an anti-anxiety activity [14] whereas the number of entries to closed arms and the time spent in closed arms are regarded as an explorative action. Like the results observed in the staircase tests, the Pericarpium zanthoxyli extract caused clear inhibition of anxiety as evidenced by the fact that the Pericarpium zanthoxyli extract increased the time spent in the open arms and the number of entries to the open arms. In contrast, the time spent in the closed arms and the number of entries to closed arms was not affected by the administration of the Pericarpium zanthoxyli extract.

In terms of the potential involvement of GABA and glycine receptor in vivo, convulsion experiments employing picrotoxin and strychnine were carried out to explore the mechanism of anti-anxiety action of the extract. It is well known that picrotoxin binds to the GABA receptor complex and inhibits the associated chloride channel activity, thereby inducing convulsion
[26]. In the present study, the Pericarpium zanthoxyli extract had no effect on the picrotoxininduced convulsion, indicating its anti-anxiety action may not be mediated by GABA receptor. On the other hand, strychnine acts as a specific antagonist of glycine receptor and binding of strychnine to glycine receptor causes the inhibition of chloride channel associated with the glycine receptor, which eventually leads to convulsion [27]. In contrast to the GABA receptor-related experiments where Pericarpium zanthoxyli had no effect on the onset time of convulsion as well as the induction time of death, it significantly increased the latency of convulsion and the time lag before death-in the strychnineinduced convulsion experiments. These results strongly suggest that some active principles in the extract may readily bind glycine receptor in the brain, activate the glycine receptor which induces opening of chloride channel, and inhibit the strychnine-induced convulsion.

In the Rotarod test, the Pericarpium zanthoxyli extract did not affect the animal's ability to remain on the Rotarod, suggesting it has little muscle relaxant activity. The present results suggest that the extract may activate strychninesensitive glycine receptor in mouse brain, and thereby induce anti-anxiety effect in vivo. However, we cannot rule out the possibility that the extract may affect other proteins that are important in the regulation of anxiety.

\section{CONCLUSION}

Pericarpium zanthoxyli extract exerts a significant anti-anxiety action. Such an action may be due to its binding to and activation of strychnine-sensitive glycine receptor in vivo; however, it has little effect on the GABA receptor system under the experimental conditions used in the present study. Taken together, these results suggest that the Pericarpium zanthoxyli extract may be beneficial for the control of anxiety in clinical situations but further studies are required to ascertain this.

\section{CONFLICT OF INTEREST}

No conflict of interest associated with this work.

\section{CONTRIBUTION OF AUTHORS}

We declare that this work was done by the authors named in this article and all liabilities pertaining to claims relating to the content of this article will be borne by the authors. 


\section{REFERENCES}

1. Yang X. Aroma constituents and alkylamides of red and green Huajiao (Zanthoxylum bungeanum and Zanthoxylum schinifolium). J Agric Food Chem 2008; 56: 1689-1696.

2. Chung J-W, Oh JU, Lee S, Kim S-J. Inhibition of inducible nitric oxide synthase, cyclooxygenase-2 and lipid peroxidation by methanol extract of Pericarpium zanthoxyli. Trop J Pharma Res 2013; 12: 369-375.

3. Lan $Y$, Wu $Q$, Mao $Y Q$, Wang $Q$, An J, Chen $Y Y$, Wang WP, Zhao BC, Liu N, Zhang YW. Cytotoxicity and enhancement activity of essential oil from Zanthoxylum bungeanum Maxim. as a natural transdermal penetration enhancer. J Zhejiang Univ-Sci B (Biomed \& Biotechnol) 2014; 15: 153-164.

4. Gong $Y$, Huang $Y$, Zhou L, Shi X, Guo Z, Wang M, Jiang $W$. Chemical composition and antifungal activity of the fruit oil of Zanthoxylum bungeanum Maxim. (Rutaceae) from China. J Essent Oil Res 2009; 21: 174-178.

5. Wei S, Zhang $H$, Wang $Y$, Wang L, Li $X$, Wang $Y$, Zhang $H$, Xu $X$, Shi $Y$. Ultrasonic nebulization extractionheating gas flow transfer-headspace single drop microextraction of essential oil from pericarp of Zanthoxylum bungeanum Maxim. J Chromatogr A 2011; 1218: 4599-4605.

6. Zhu RX, Zhong $K$, Zeng WC, He $X Y$, Gu XQ, Zhao ZF, Gao H. Essential oil composition and antibacterial activity of Zanthoxylum bungeanum. Afr J Microbiol Res 2011; 5: 4631-4637.

7. Cheong, Bo-seop Shin, Min-gyo. Iconographical Folk Medicine Encyclopedia, Younglim Co., Ltd. P 795-796, 1999;

8. New Oriental Medicine Handbook, Traditional Oriental Medicine Database, Scientific Research Center of Natural Substances, Seoul University, 1999.

9. Zhang $M$, Chen $Y$, Zhu Z, Chen G. Pharmacological studies on warming the middle-jiao to alleviate pain by Pericarpium zanthoxyli. Zhongguo Zhong Yao Za Zhi. 1991; 16: 493-497.

10. Wang CF, Yang K, Zhang HM, Cao J, Fang R, Liu ZL, Du SS, Wang YY, Deng ZW, Zhou L. Components and insecticidal activity against the maize weevils of Zanthoxylum schinifolium fruits and leaves. Molecules 2011; 16: 3077-3077.

11. Kim HR, Kim JM, Kim MS, Hwang JK, Yang SH, Kim HJ, Lee DS, Oh H, Kim YC, Ryu DG et al. Inhibitory effect of Pericarpium zanthoxyli extract on adipocyte differentiation. Int J Mol Med 2014; 33: 1140-1146.

12. Griffiths RR, Weerts EM. Benzodiazepine selfadministration in humans and laboratory animals - implications for problems of long-term use and abuse. Psychopharmacology (Berl) 1997; 134: 1-37.

13. Simiand J, Keane PE, Morre M. The staircase test in mice: a simple and efficient procedure for primary screening of anxiolytic agents. Psychopharmacology 1984; 84: 48-53.

14. Pellow S, Chopin PH, File SE, Briley M. Validation of open:closed entries in an elevated plus maze as a measure of anxiety in the rat. J Neurosci Methods 1985; 14: 149-167.

15. Bigler ED. Comparison of effects of bicuculline, strychnine, and picrotoxin with those of pentylenetetrazol on photically evoked afterdischarges. Epilepsia 1977; 18: 465-470.

16. Usunoff G, Atsev E, Tchavdarov D. On the mechanism of picrotoxin epileptic seizure (macro- and microelectrode investigations). Electroencephalogr Clin Neurophysiol 1969; 27: 444-447.

17. Tsuda M, Suzuki T, Misawa M, Nagase H. Involvement of the opioid in the anxiolytic effect of diazepam in mice. Eur J Pharmacol 1996; 307: 7-14.

18. National Pharmacopoeia Committtee. Chinese Pharmacopoeia 2005; I: 116.

19. Yamazaki E, Inagaki M, Kurita $O$, Inoue T. Antioxidant activity of Japanese pepper (Zanthoxylum piperitum DC.) fruit. Food Chem 2006; 100 (1); 171-177.

20. Liu X, Zhang Z, Duan Y, Liu Q, Cui J. Antioxidant activities of herbs and spices from commercial sources. Shipin Kexue 2002; 23 (1): 143-145.

21. Setzer WN, Schmidt JM, Eiter LC, Haber WA. The leaf oil composition of Zanthoxylum fagara (L.) Sarg. From Monteverde, Costa Rica, and its biological activities. J Essent Oil Res 2005; 17 (3): 333-335.

22. Mi $X$, Gong $Z$, Zhang $W$, Zhang $X$. Study on the extraction, separation and antimicrobial effect of volatile oil from Zanthoxylum bungeanum (Maxim). Nanjing Shida Xuebao, Ziran Kexueban 2004; 27 (4): 63-66.

23. Chen D, Yang G. Quinoline alkaloids isolated from Zanthoxylum as antiviral agents for the treatment of hepatitis B. Faming Zhuanli Shenqing Gongkai Shuomingshu, 2005; 8: CN 1698610A 20051123.

24. Oriowo MA. Anti-inflammatory activity of piperonyl-4acrylic isobutyl amide, an extract from Zanthoxylum zanthoxyloides. Planta Med 1982; 44: 54-56.

25. Setzer WN. Essentail oils and anxiolytic aromatheraphy. Nat Prod Commun 2009; 4:1305-1316.

26. Pericic D, Manev H, Bujas M. Gonadal hormones and picrotoxin-induced in male and female rat. Brain Res 1996; 14: 174-179.

27. White WF, O'Gorman S, Roe AW. The three dimensional autoradiographic localization of quench-corrected glycine $3 \mathrm{H}$-strychnine as a ligand. J Neurosci 1990; 10: 795-813. 